\title{
Efficient lightweight supercapacitor with compression stability
}

\author{
Kaiyuan Shi, Xuan Yang, Emily D. Cranston and Igor Zhitomirsky
}

DOI: $10.1002 / \mathrm{adfm} .201602103$

This is the pre-peer reviewed version of the following article: Shi et al., Efficient lightweight supercapacitor with compression stability, Adv. Funct. Mater. 2016, 26, 6437-6445, which has been published in final form at DOI: 10.1002/adfm.201602103. This article may be used for non-commercial purposes in accordance with Wiley Terms and Conditions for Self- Archiving. 


\section{WILEY-VCH}

\section{Article type: Full Paper}

\section{Efficient lightweight supercapacitor with compression stability}

Kaiyuan Shi ${ }^{a \dagger}$, Xuan Yang ${ }^{b \dagger}$, Emily D. Cranston ${ }^{b}$ and Igor Zhitomirsky ${ }^{a *}$

$\uparrow$ These authors contributed equally to this work

Kaiyuan Shi, Prof. Igor Zhitomirsky*

Department of Materials Science and Engineering, McMaster University, Hamilton, L8S 4L7, Canada

E-mail: zhitom@mcmaster.ca

Phone: 1- (905)-525-9140 ext. 23914

Xuan Yang, Prof. Emily D. Cranston

Department of Chemical Engineering, McMaster University, Hamilton, L8S 4L7, Canada

E-mail: ecranst@mcmaster.ca

Keywords: cellulose, nanocrystal, polypyrrole, supercapacitor, aerogel 


\section{WILEY-VCH}

\section{Abstract}

This article reports the fabrication of an electrochemical supercapacitor (ES) with high gravimetric and areal capacitance, achieved at a high mass ratio of active material to current collector. The active material, polypyrrole, was in situ polymerized in an aerogel-based current collector composed of crosslinked cellulose nanocrystals (CNC) and multiwalled carbon nanotubes (MWCNT). Mechanical robustness, flexibility and low impedance of the current collectors were achieved by the chemical crosslinking of $\mathrm{CNC}$ aerogels and efficient dispersion of MWCNT through the use of bile acid as a dispersant. Furthermore, the advanced electrode design resulted in low contact resistance. A single electrode areal capacitance of $2.1 \mathrm{~F} \mathrm{~cm}^{-2}$ was obtained at an active mass loading of $17.8 \mathrm{mg} \mathrm{cm}^{-2}$ and an active material to current collector mass ratio of 0.57. Large area ES electrodes and devices showed flexibility, excellent compression stability at $80 \%$ compression, and electrochemical cyclic stability over 5000 cycles. Moreover, good retention of capacitive properties was achieved at high charge-discharge rates and during compression cycling. The results of this investigation pave the way for the fabrication of advanced lightweight ES, which can be used for energy storage in wearable electronic devices and other applications. 


\section{WILEY-VCH}

\section{Introduction}

Electrochemical supercapacitors (ES) are currently under development for energy storage in electronic devices, hybrid and electric vehicles, ${ }^{[1-3]}$ capacitive deionization of water $^{[4,5]}$ and capacitive dye removal from aqueous solutions. ${ }^{[6,7]}$ Fundamental investigations have been focused on the development of advanced electrode materials, electrolytes, device design and modeling. ${ }^{[1,2,8-11]}$ There are excellent review papers, describing recent advances in ES technology; ${ }^{[3,10,12,13]}$ however, the main challenge now faced by researchers is to achieve good capacitive behavior at high active mass loadings and low mass of current collectors. There is a growing need for ES with low electrode material resistance and low contact resistance, good capacitance retention at high charge-discharge rates and cyclic stability. New applications of supercapacitors, such as wearable electronics, have generated a need for flexible and compressible devices with high compression stability and stable capacitive performance during compression.

Increasing attention to environmental issues has recently driven researchers to develop more renewable, biodegradable and environmentally-friendlier electronic devices. Nanocellulose is one emerging renewable material, which has advantages of low cost, high porosity, large specific surface area and low density. With these advantages, nanocellulose has attracted great interest as the lightweight electrode support for ES applications. ${ }^{[14,15]}$ The cellulose is usually combined with conductive additives, such as carbon nanotubes and graphene. ${ }^{[15-19]}$ The dispersion of carbon nanotubes and their mixing with cellulose on the nanometric scale is one of the most difficult challenges for creating lightweight conductive current collectors. Moreover, the use of nanocellulose-based electrodes often introduces problems related to the integration of ES in modules and electric circuits due to high contact resistance.

Nanocellulose-based current collectors must be loaded with electrochemically active materials for energy storage. Several investigations have focused on the fabrication of 


\section{WILEY-VCH}

polypyrrole (PPy)-nanocellulose composites. ${ }^{[20-26]}$ Recent progress in preparing nanocellulose-based aerogels and foams, ${ }^{[27-32]}$ has generated interest in their application as advanced supports for ES electrodes. ${ }^{[33-35]}$ Aerogels can provide high surface area and controllable pore structure, facilitating electrolyte ion transportation. ${ }^{[36]}$ Nanocellulose aerogels have been impregnated with active materials using layer-by-layer self assembly ${ }^{[31,37]}$ and electrodeposition. ${ }^{[34]}$ The progress in the nanocellulose aerogel fabrication methods may address the needs for novel ES devices to have both advanced capacitive and mechanical properties.

The goal of this investigation was to fabricate lightweight ES devices, using cellulose nanocrystal $(\mathrm{CNC})$ aerogels with enhanced mechanical properties as electrode supports. We have targeted the fabrication of flexible and reversibly compressible electrodes and devices with high capacitance, low contact resistance, high active mass loading and high ratio of active material mass to the current collector mass. Moving towards this goal we fabricated conductive cellulose aerogels by covalently crosslinking two orthogonally surface-modified types of CNC and trapped multiwalled carbon nanotubes (MWCNT) into the aerogel structure during processing. The effect of polymerizing Ppy inside the aerogel as the capacitive component was investigated. The low impedance of the aerogel resulted from efficient MWCNT dispersion, achieved by the use of a bile acid, which allowed excellent dispersion due to its unique structure and adsorption mechanism. The microstructure of the crosslinked CNC-MWCNT aerogels and efficient loading with PPy active material offered highly advantageous features for applications as ES current collectors.

Using this new strategy, we have fabricated highly flexible and reversibly compressible electrodes and devices with excellent compression stability at $80 \%$ compression. We report the fabrication of electrodes with capacitance of $2.1 \mathrm{~F} \mathrm{~cm}^{-2}$ and mass ratio of active material/current collector of 0.57 . The results presented below indicate superior capacitance retention of electrodes and devices at high charge-discharge rates and good electrochemical 


\section{WILEY-VCH}

cyclic stability. We report good capacitance retention during multiple compression cycles. This study lays the groundwork for the fabrication of advanced ES devices, combining excellent capacitive and mechanical properties, which can be used for automotive applications, wearable electronic devices, capacitive deionization of water and other applications.

\section{Results and Discussion}

The CNC aerogels were assembled based on the chemical crosslinking of aldehydemodified $\mathrm{CNC}(\mathrm{CHO}-\mathrm{CNC})$ and hydrazide-modified $\mathrm{CNC}\left(\mathrm{NHNH}_{2}-\mathrm{CNC}\right)$. This sol-gel crosslinking strategy allows for the fabrication of aerogels with enhanced mechanical properties due to chemical bonding (hydrazone crosslinks) between two different types of CNC. Moreover, it offers the opportunity to incorporate MWCNT into the CNC aerogel by first dispersing MWCNT in the CNC suspensions and then combining the suspensions to induce crosslinking. The incorporation of MWCNT was beneficial due to its high conductivity and potential reinforcing ability. However, the success of this strategy was largely dependent on the efficient dispersion of MWCNT in the CNC suspensions and as such, different dispersing aids were tested. 


\section{WILEY-VCH}

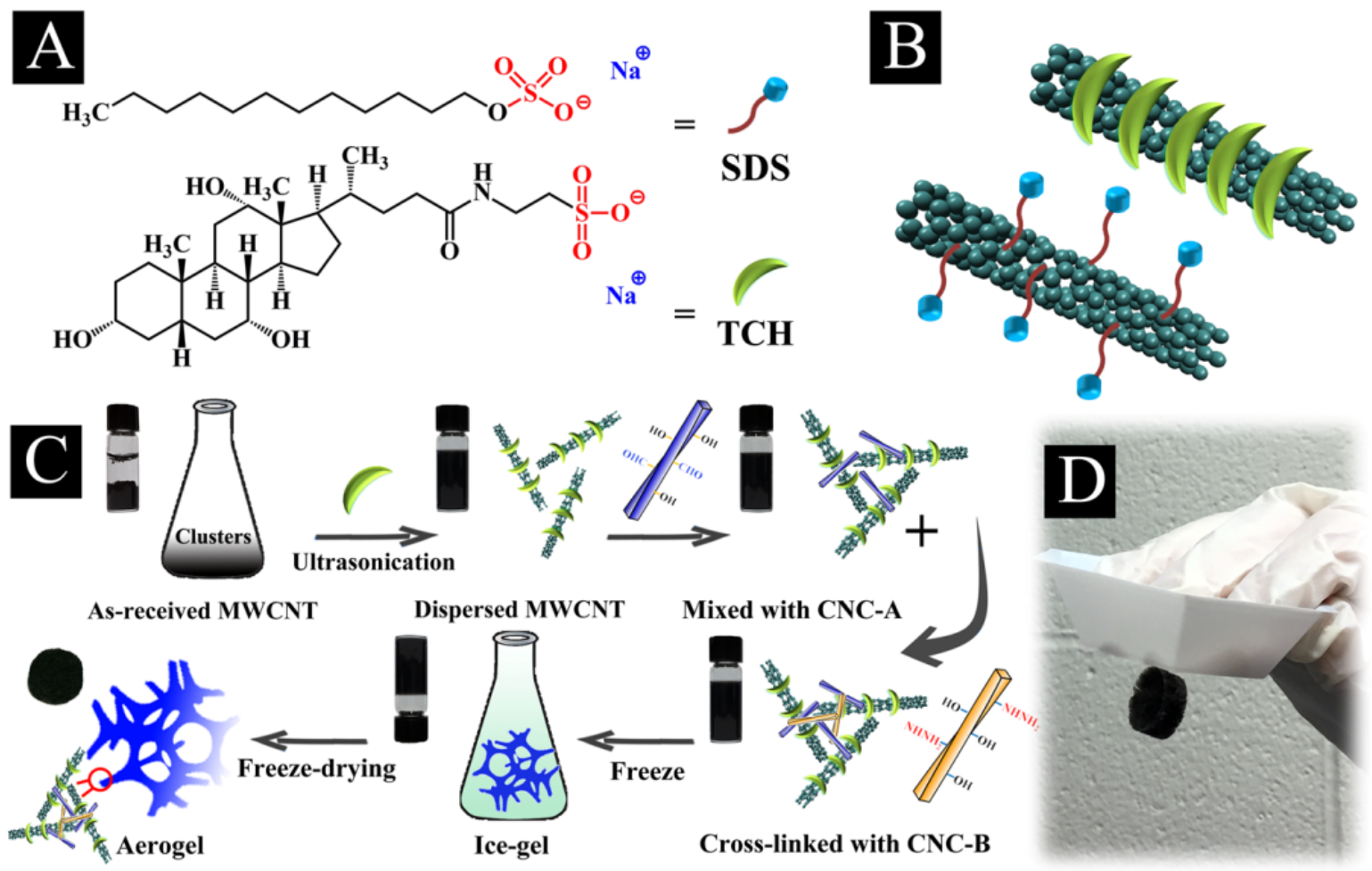

Figure 1. (A) Chemical structures and (B) MWCNT dispersion mechanisms of SDS and TCH, (C) scheme of CNC-MWCNT aerogel fabrication method, (D) aerogel with a density of $21 \pm$ $3 \mathrm{mg} \mathrm{cm}^{-3}$ attached to a weighing dish through static electricity.

Two dispersants were employed in this work and their chemical structures are shown in Figure 1A. Sodium dodecyl sulfate (SDS) is a typical head-and-tail surfactant, which is composed of a hydrophobic tail and a polar head group. Taurocholic acid sodium salt (TCH) belongs to the family of bile acids; the structure of $\mathrm{TCH}$ includes a rigid steroid backbone, which possesses a hydrophobic convex side and hydrophilic concave side. ${ }^{[38]}$ The hydroxyl groups are located on the concave side of the steroid backbone. ${ }^{[38]}$ The anionic properties of SDS and $\mathrm{TCH}$ are attributed to their $\mathrm{SO}_{3}{ }^{-}$groups making these dispersants able to disperse MWCNT based on an electrosteric stabilization mechanism, due to adsorbed SDS or TCH on the MWCNT surface. ${ }^{[39]}$

Similar to other head-and-tail surfactants, SDS adsorbs on carbon nanotube surfaces in a perpendicular orientation ${ }^{[38]}$ (Figure 1B). Such orientation results in the formation of 


\section{WILEY-VCH}

insulating layers, which are detrimental for applications based on MWCNT electrical conductivity. Conversely, investigations of single walled carbon nanotubes (SWCNT) dispersions showed that bile acids instead wrap around SWCNT to form a ring ${ }^{[38]}$ leading to enhanced adsorption on the SWCNT surface and superior dispersion, compared to the linear head-and-tail surfactants. ${ }^{[38]}$ Previously, it was demonstrated that bile acids outperform other dispersants in the dispersion of SWCNT. ${ }^{[40]}$ In another study it was found that TCH specifically allows for excellent dispersion of $\mathrm{MWCNT}^{[39]}$ and it was suggested that similar adsorption mechanisms govern the adsorption of TCH on both SWCNT and MWCNT. Using sedimentation tests we found that TCH and SDS showed excellent dispersion of MWCNT in CNC suspensions and built on this success by preparing aerogels composed of CNC with SDS or TCH-adsorbed MWCNT. Figure $1 \mathrm{C}$ shows the steps in the fabrication of CNC aerogels containing MWCNT, described in the Experimental Section, and Figure 1D shows the final appearance and lightweight nature of the CNC-MWCNT aerogels.

The diameter of the aerogel disks was varied in the range of 1-30 $\mathrm{cm}$ using different moulds during the freezing step (Figure 1C) which is significant because the ability to form large area ES devices is important for automotive applications and for energy storage in wearable electronics. We were able to synthesize the aerogel within (and around) a stainless steel mesh by incorporating the mesh before the freezing and drying steps (Figure 2A); we believe this will be beneficial for the reduction of the contact resistance of the aerogel electrodes and their integration into modules and circuits. The SEM image of the aerogel cross section indicates that the aerogel was formed uniformly inside the mesh and the mesh was well-integrated into the aerogel structure (Figure 2B). The incorporated mesh allowed the use of soldering for the integration of the electrodes in cell modules and circuits with reduced contact resistance. 


\section{WILEY-VCH}

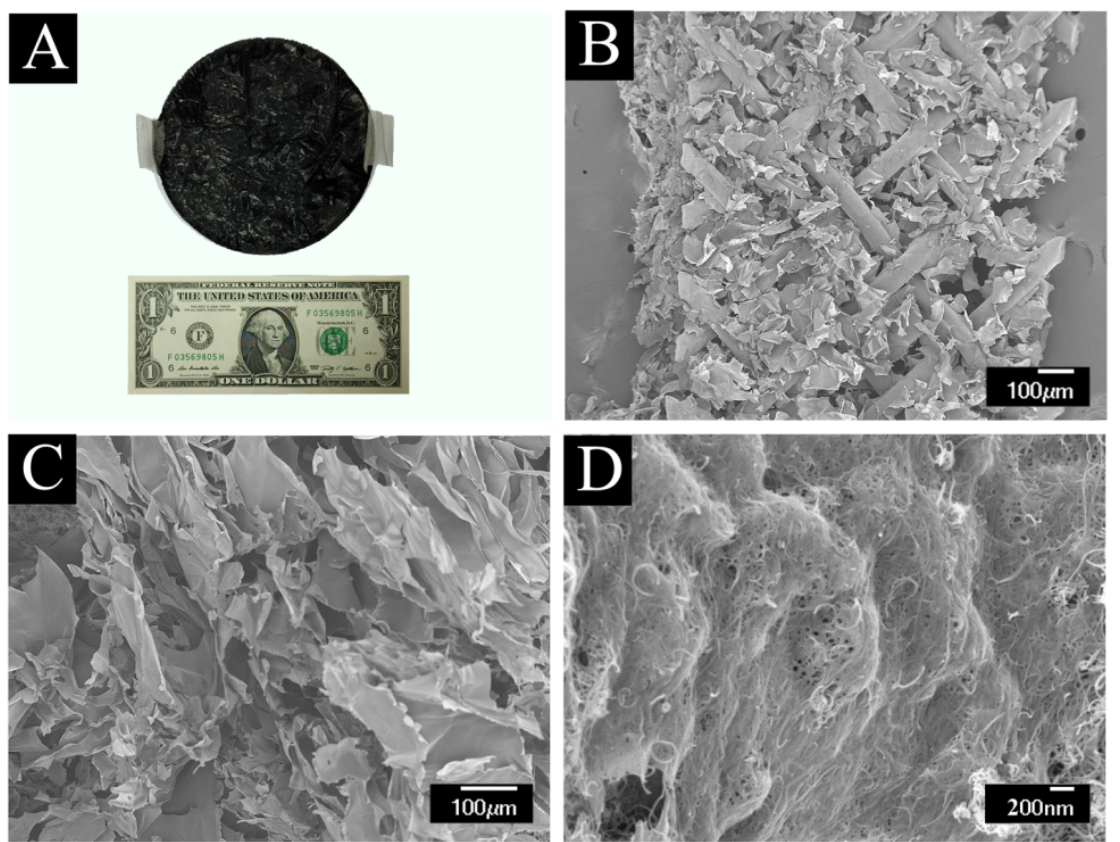

Figure 2. (A) CNC-MWCNT aerogel, prepared using TCH, containing a $0.2 \mathrm{~mm}$ thickness stainless steel mesh current collector and SEM images of (B) cross section, showing the stainless steel mesh inside the aerogel and (C, D) aerogel cross section at different magnifications.

Further SEM studies showed flaky morphology of the aerogels and porous microstructure (Figure 2C), which is beneficial for the loading of the aerogel with a capacitive PPy material. The SEM images of the individual flakes at higher magnification showed that they contained well-dispersed MWCNT in the CNC matrix (Figure 2D). The MWCNT formed a conductive network, which was important for the application of the aerogel as a current collector for the ES electrodes. SEM did not show significant microstructural differences based on whether TCH or SDS was used as the MWCNT dispersant (Figures 2C and 2D and Supporting Information Figures S1A and S1B). However, electrochemical studies and mechanical testing of aerogels loaded with PPy, showed improved performance of the aerogel formed in the presence of $\mathrm{TCH}$ (discussed further below). We believe the difference can be attributed to the wrapping mechanism of $\mathrm{TCH}$ adsorption, which allowed for reduced interface resistance and better integration of TCH into the aerogel structure. 


\section{WILEY-VCH}
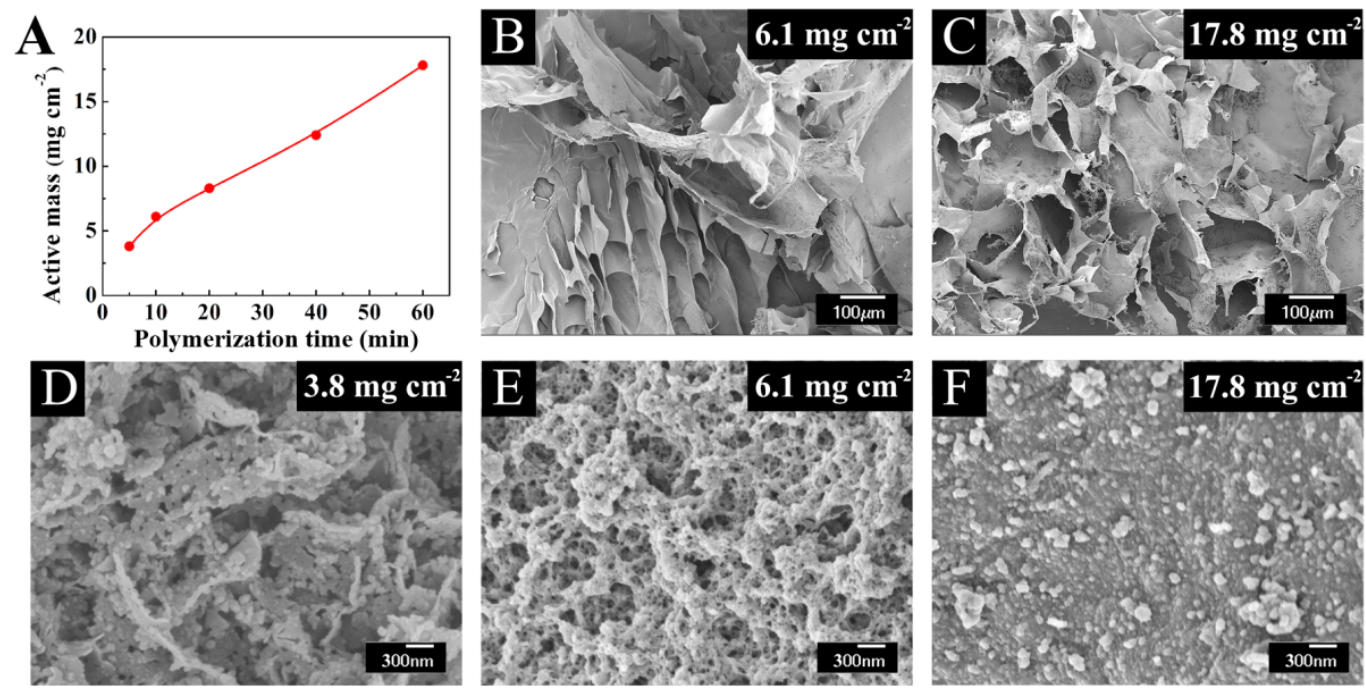

Figure 3. (A) Mass of PPy, deposited on CNC-MWCNT aerogel, prepared using TCH, versus polymerization time and (B-E) SEM images of the CNC-MWCNT aerogels with PPy mass loadings of $3.8,6.1$ and $17.8 \mathrm{mg} \mathrm{cm}^{-2}$ at different magnifications.

The aerogels were loaded with PPy by an in situ chemical polymerization method. CNC-MWCNT aerogels were placed in purified water containing the dopant Tiron; Py was added followed by the initiator, APS, and the reaction was allowed to occur for 5-60 min depending on the desired loading. The PPy mass loading increased with increasing polymerizations time as shown in Figure 3A and Supporting Information Figure S2. Therefore, the active mass loading can be varied and controlled in a straightforward manner. The low magnification SEM images (Figures 3B and 3C) showed that the microstructure of the PPy loaded aerogels, prepared using TCH-dispersed MWCNT, was similar to the microstructure of the original aerogels before impregnation. Even after in situ polymerization, the microstructure contained large porous channels with diameter of 30-100 $\mu \mathrm{m}$. Such channels could improve electrolyte access to the active material. The analysis of the microstructure of aerogels, prepared using SDS-dispersed MWCNT showed significant blocking of the large pores (Supporting Information Figure S3). The comparison of the SEM images of the aerogel flakes at higher magnification for PPy loaded (Figures 3D-3F) and unloaded aerogels (Figure 2D) showed that the flakes were coated with PPy. At low mass 


\section{WILEY-VCH}

loading the coating microstructure was porous with a typical pore size of 100-300 nm (Figure 3D). The porosity of the coatings decreased with increasing active mass loadings (Figure 3E).

Further increase in the mass loadings resulted in the formation of relatively dense coatings

(Figure 3F).
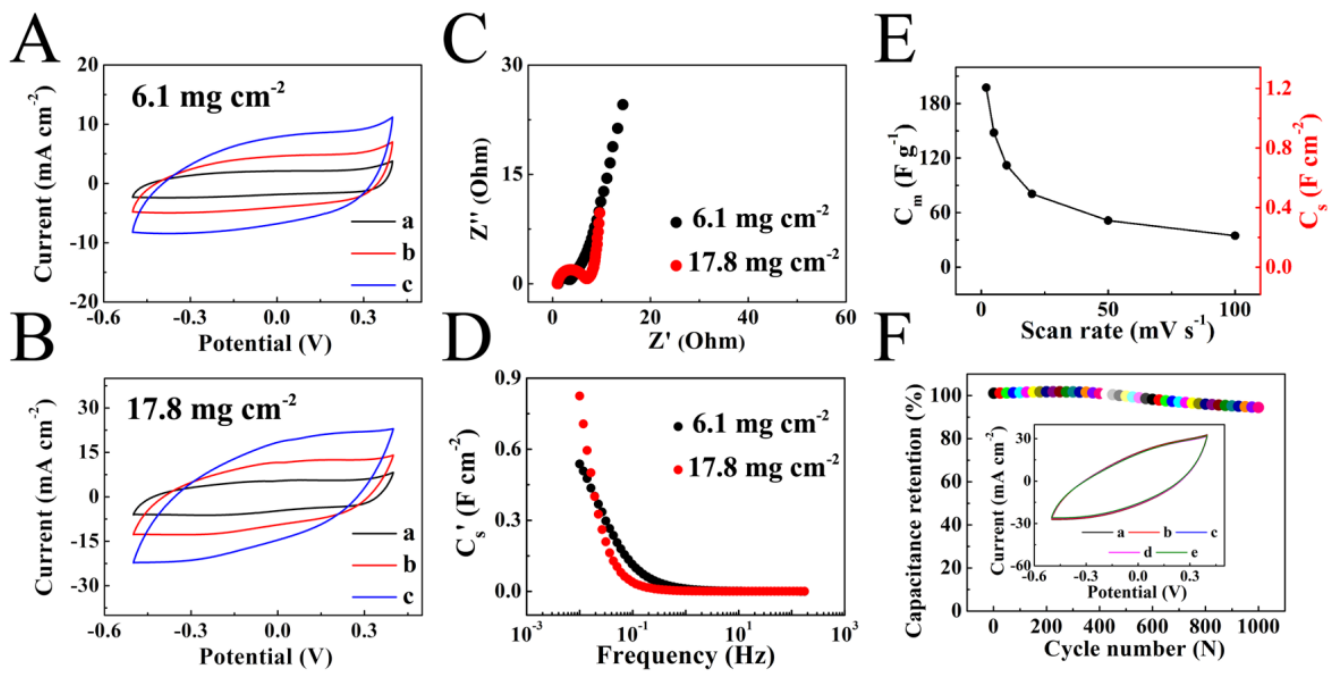

Figure 4. (A,B) CVs for CNC-MWCNT aerogels, prepared using TCH, with PPy loadings of (A) 6.1 and (B) $17.8 \mathrm{mg} \mathrm{cm}^{-2}$ at scan rates of (a) 2, (b) 5 and (c) $10 \mathrm{mV} \mathrm{s}^{-1}$. (C) Nyquist plots of complex impedance and (D) $\mathrm{C}_{\mathrm{s}}{ }^{\prime}$ calculated from the impedance data for aerogel with PPy loadings of 6.1 and $17.8 \mathrm{mg} \mathrm{cm}^{-2}$. (E) $\mathrm{C}_{\mathrm{m}}$ and $\mathrm{C}_{\mathrm{s}}$ calculated from CVs versus scan rate, $(\mathrm{F})$ capacitance retention versus cycle number (inset shows corresponding $\mathrm{CVs}$ at $50 \mathrm{mV} \mathrm{s}{ }^{-1}$ after (a) $1^{\text {st }}$, (b) $250^{\text {th }}$, (c) $500^{\text {th }}$, (d) $750^{\text {th }}$ and (e) $1000^{\text {th }}$ cycles for aerogel with PPy loading of 6.1 $\mathrm{mg} \mathrm{cm} \mathrm{cm}^{-2}$.

The results of electrochemical testing of the electrodes, prepared using TCH-dispersed MWCNT in CNC aerogels with different PPy mass loadings are shown in Figure 4A and 4B. The nearly box shape cyclic voltammograms (CVs) (Figures 4A and 4B) and increase in current with increasing scan rate indicated good capacitive behavior in a voltage window of $0.9 \mathrm{~V}$. The impedance analysis (Figures 4C and 4D) at different frequencies showed relatively low electrode resistance $\mathrm{R}=\mathrm{Z}$. The Nyquist plot for the electrode with the highest active mass loading of $17.8 \mathrm{mg} \mathrm{cm}^{-2}$ showed larger resistance, compared to the electrodes with lower mass loadings. The higher resistance likely results from lower porosity of the PPy coating on the aerogel flakes (Figure 3F). The lower Z" for the $17.8 \mathrm{mg} \mathrm{cm}^{-2}$ electrode at low frequencies is attributed to higher capacitance (Figure 4D). The capacitance decreased with 


\section{WILEY-VCH}

increasing frequency (Figure 4D) and increasing scan rate (Figure 4E) due to limited diffusion through the small pores of the PPy coating. The electrodes showed good cyclic stability (Figure 4F). The CV data for the electrode with active mass of $6.1 \mathrm{mg} \mathrm{cm}^{-2}$ showed the capacitance retention of $94.5 \%$ after 1000 cycles. In comparison, the electrodes, prepared using SDS-dispersed MWCNT in CNC aerogels showed lower capacitance at similar active mass loadings (Supporting Information Figure S4). The lower capacitance can result from blocking of large pores in the surface layers of the CNC-MWCNT aerogel with PPy. Therefore, further investigations were focused on the electrodes prepared using TCH.
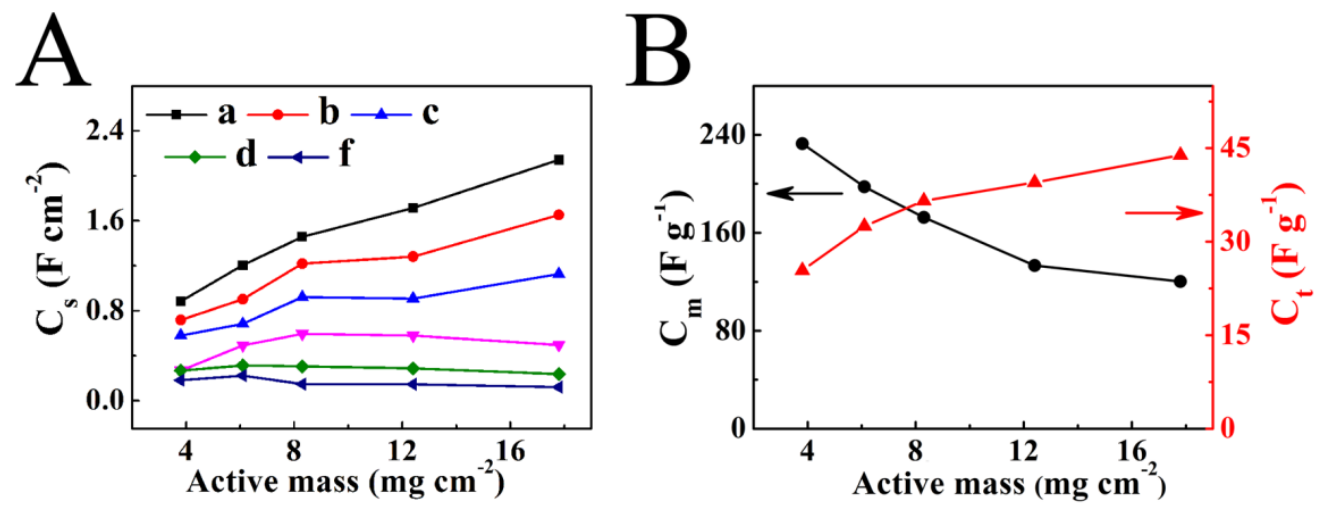

Figure 5. (A) $\mathrm{C}_{\mathrm{s}}$ versus active mass of PPy, grown on CNC-MWCNT aerogel, prepared using $\mathrm{TCH}$, at scan rates of (a) 2, (b) 5 , (c) 10 , (d) 20 , (e) 50 and (f) $100 \mathrm{mV} \mathrm{s}^{-1}$. (B) $\mathrm{C}_{\mathrm{m}}$ and $\mathrm{C}_{\mathrm{t}}$ at 2 $\mathrm{mV} \mathrm{s}^{-1}$ versus active mass of PPy, grown on CNC-MWCNT aerogel.

The area normalized capacitance increased with increasing active mass loading (Figure 5A), indicating good material utilization. The capacitance of $2.1 \mathrm{~F} \mathrm{~cm}^{-2}$ was obtained at a scan rate of $2 \mathrm{mV} \mathrm{s}^{-1}$ and active mass loading of $17.8 \mathrm{mg} \mathrm{cm}^{-2}$ and the mass ratio of active material to current collector was 0.57 . The mass of the current collector used in all calculations included the stainless steel mesh, which was used to connect the supercapacitor electrodes to the circuit. In contrast, other studies with aerogel/foam current collectors ${ }^{[41]}$ have required additional materials, such as silver paste and metal foil, for electrical connection, which adds extra mass to the electrodes but is not accounted for in capacitance calculations. The high active material to current collector mass ratio is an important factor for 


\section{WILEY-VCH}

practical applications of supercapacitors ${ }^{[42]}$ and is much higher in this work than previously reported. In many investigations ${ }^{[42]}$ thin film electrodes were used with active mass loadings of $0.001-1 \mathrm{mg} \mathrm{cm}^{-2}$ and active material to current collector mass ratio of $6.3 \times 10^{-5}-1.3 \times 10^{-2}$. The use of Ni foam as a current collector ${ }^{[42]}$ allowed for PPy mass loadings of 20-30 $\mathrm{mg} \mathrm{cm}^{-2}$ and active material to current collector mass ratio of $0.28-0.41$; this current work surpasses past work by achieving a mass ratio of 0.57 and highlights that the development of aerogel based electrodes is promising for the fabrication of lightweight ES devices. The ES electrodes showed relatively high active mass normalized gravimetric capacitance $\mathrm{C}_{\mathrm{m}}$ of $232.7 \mathrm{~F} \mathrm{~g}^{-1}$ at $3.8 \mathrm{mg} \mathrm{cm}$, which decreased with increasing active mass (Figure 5B). However, the gravimetric capacitance, normalized by total electrode mass, including current collector and active material, increased with increasing mass loading. The capacitance, normalized by the total mass of active material and current collector $\mathrm{C}_{\mathrm{t}}=43.9 \mathrm{~F} \mathrm{~g}^{-1}$ was obtained at active mass loading of $17.8 \mathrm{mg} \mathrm{cm}^{-2}$. 
A
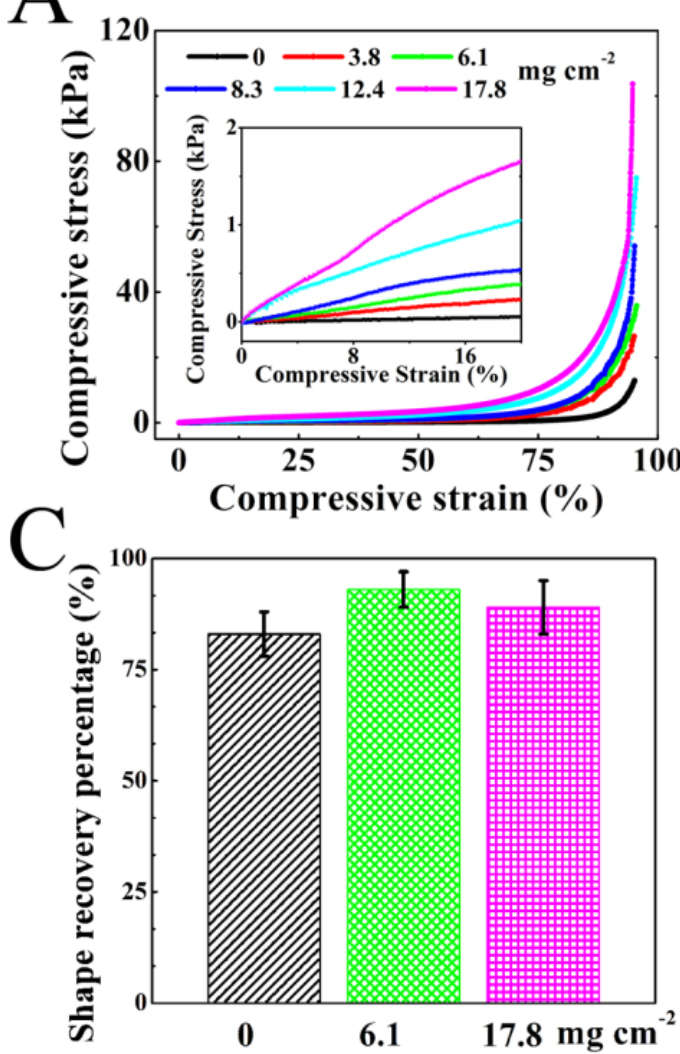

$\mathrm{B}$
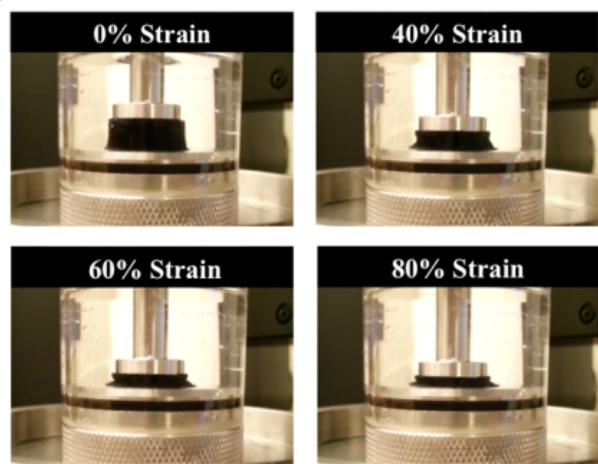

$80 \%$ Strain

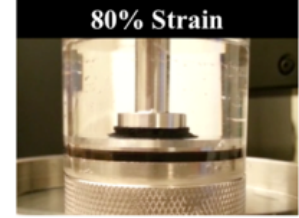

$\mathrm{D}$

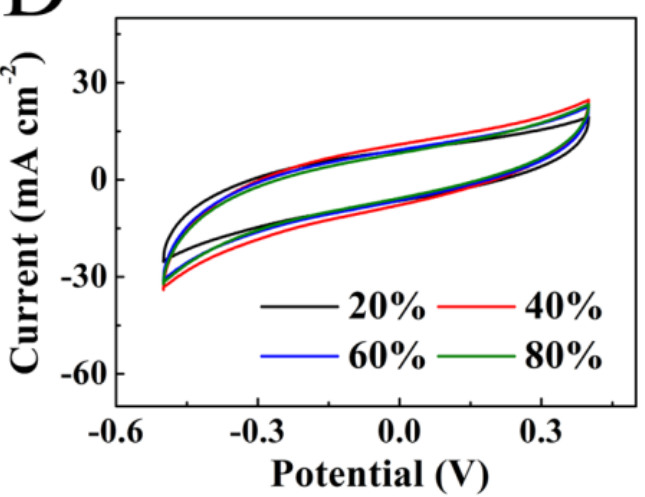

Figure 6. (A) Compressive stress-strain curves for CNC-MWCNT aerogels, prepared using $\mathrm{TCH}$, with different PPy loadings in the range of $0-17.8 \mathrm{mg} \mathrm{cm}^{-2}$, (inset shows initial parts of the curves). (B) Compression tests of PPy loaded CNC-MWCNT aerogels at 0-80\% strains. (C) Shape recovery of pure CNC-MWCNT aerogel with PPy contents of $0,6.1$ and $17.8 \mathrm{mg}$ $\mathrm{cm}^{-2}$ after 400 cyclic compressions from $0 \%$ to $80 \%$ strain. (D) CVs for CNC-MWCNT aerogel with PPy mass loading of $6.1 \mathrm{mg} \mathrm{cm}^{-2}$ at a scan rate of $20 \mathrm{mV} \mathrm{s}^{-1}$ under different strains $(20-80 \%)$. All the tests were carried out in $0.5 \mathrm{M} \mathrm{Na}_{2} \mathrm{SO}_{4}$ solutions.

The use of CNC-MWCNT aerogels allowed for the fabrication of flexible and reversibly compressible electrodes and devices. The CNC-MWCNT aerogels, prepared using $\mathrm{TCH}$ as the dispersant showed improved mechanical properties (Figure 6), compared to the electrodes, prepared using SDS (Supporting Information, Figure S5) which is indirect evidence for better dispersion of MWCNT throughout the aerogel structure with TCH. Figure 6A shows that CNC-MWCNT-PPy aerogels impregnated with PPy display the typical stressstrain behavior of an open-cell foam. ${ }^{[43-46]}$ The aerogel with high PPy loading showed a higher 


\section{WILEY-VCH}

compressive modulus in the elastic region (Figure 6A, inset) and higher compressive stress (at same strain) in the plastic stiffening region (Figure 6A) compared to lower PPy loadings.

Shape recovery of the hybrid aerogels was tested through cyclic compression tests (400 cycles between $0 \%$ and $80 \%$ strain) in electrolyte as shown in Figures 6B and 6C. The aerogels with PPy mass loadings of $0,6.1$ and $17.8 \mathrm{mg} \mathrm{cm}^{-2}$ maintained $85 \pm 5 \%, 93 \pm 4 \%$ and $89 \pm 6 \%$ of their original height after compression, respectively. The better shape recovery ability of the latter two aerogels is attributed to the formation of the PPy layer around the CNC-MWCNT aerogel backbone, which likely reinforced the structure. Importantly the recovery rate is approximately $0.05 \mathrm{~cm} \mathrm{~s}^{-1}$ which is sufficient for creating small flexible devices. A cyclic compression test video (3 cycles) is provided in the Supporting Information, Video SI - Aerogel Cyclic Compression. The analysis of CVs at different strains showed an increase in the CV areas for strained aerogels in the strain range of $0-80 \%$ (Figure 6D). The capacitance increased by 16.2, 25.6, 8.2 and $4.7 \%$ at strains of 20, 40, 60 and $80 \%$, respectively, compared to original aerogels without strain. These results indicate the retention of capacitive properties at strains of $80 \%$, which is higher than that reported for the graphene foams ${ }^{[47]}$ and composite sponges ${ }^{[48,49]}$. 


\section{WILEY-VCH}

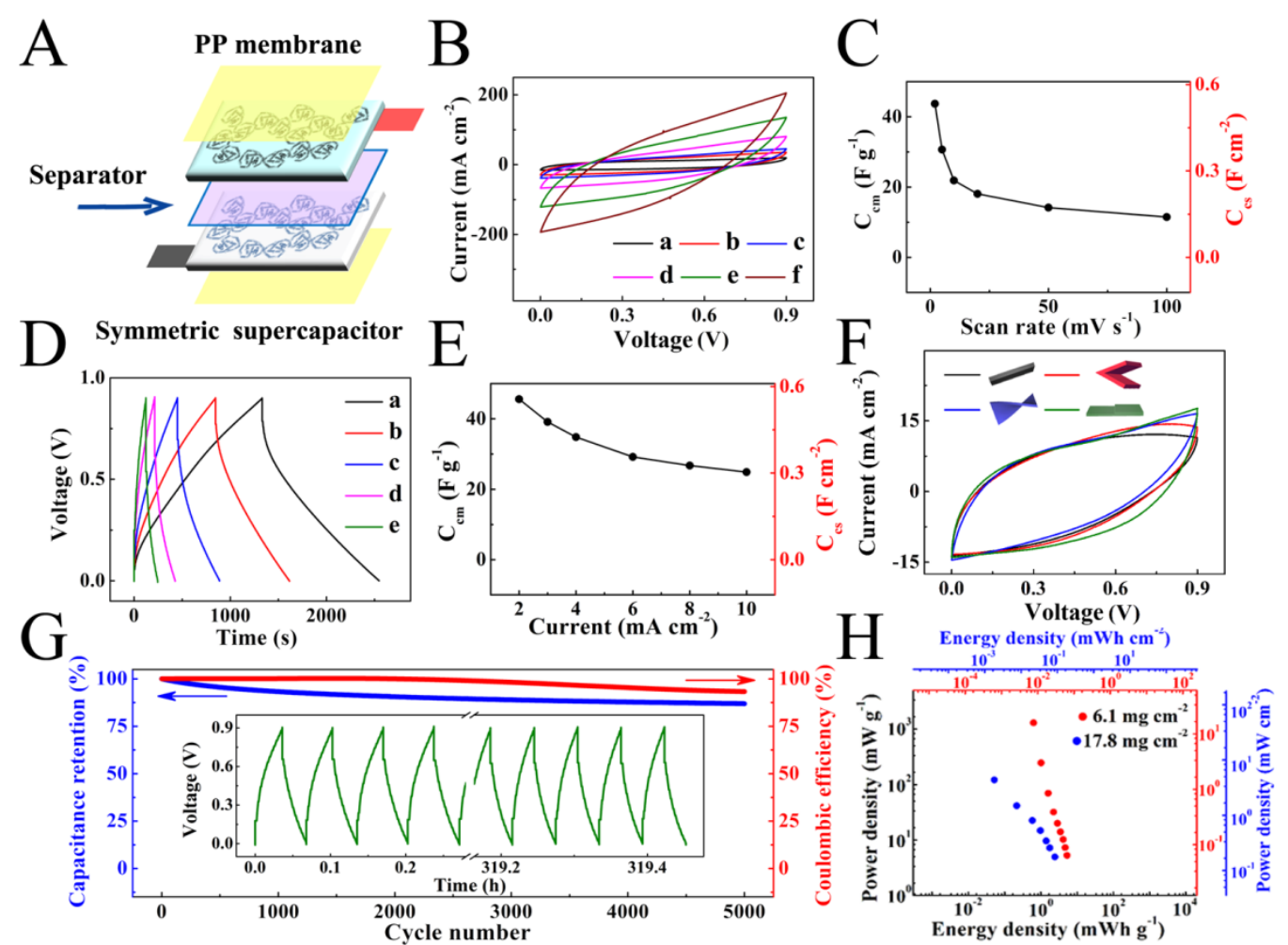

Figure 7. (A) Scheme of ES cell, (B-G) testing data for the cell with PPy mass of $6.1 \mathrm{mg} \mathrm{cm}$ for each electrode: (B) CVs at scan rates of (a) 2, (b) 5, (c) 10, (d) 20, (e) 50 and (f) $100 \mathrm{mV} \mathrm{s}^{-}$ ${ }^{1}$, (C) $\mathrm{C}_{\mathrm{cm}}$ and $\mathrm{C}_{\mathrm{cs}}$ calculated from the $\mathrm{CV}$ data versus scan rate, (D) charge-discharge behavior at current densities of (a) 2, (b) 3, (c) 4, (d) 6 and (e) $8 \mathrm{~mA} \mathrm{~cm}^{-2}$, (E) $\mathrm{C}_{\mathrm{cm}}$ and $\mathrm{C}_{\mathrm{cs}}$ calculated from the CD data versus current density, (F) CVs at a scan rate of $2 \mathrm{mV} \mathrm{s}^{-1}$ for different deformations, $(\mathrm{G})$ capacitance retention and Coulombic efficiency versus cycle number (inset shows initial and final charge-discharge curves at $15 \mathrm{~mA} \mathrm{~cm}$ ), $(\mathrm{H})$ Ragone plots for cells with PPy mass of individual electrodes of 6.1 and $17.8 \mathrm{mg} \mathrm{cm}^{-2}$.

The hybrid aerogel electrodes with PPy mass loading of $6.1 \mathrm{mg} \mathrm{cm}^{-2}$, which showed the highest compression stability (Figure 6C), were used for the fabrication of ES cells (Figure 7A). The capacitive behavior of the cells was analyzed in a voltage window of $0.9 \mathrm{~V}$ (Figures 7B-7E). At higher voltages, the CV curves deviated significantly from the box shapes and the galvanostatic charge-discharge curves were essentially non-linear (Supporting Information, Figure S6). The capacitance of $43.7 \mathrm{~F} \mathrm{~g}^{-1}\left(0.54 \mathrm{~F} \mathrm{~cm}^{-2}\right)$ was obtained (Figure 7C) at a scan rate of $2 \mathrm{mV} \mathrm{s}^{-1}$ from the $\mathrm{CV}$ data (Figure 7B) for the ES cells. The capacitance of $45.6 \mathrm{~F} \mathrm{~g}^{-1}\left(0.56 \mathrm{~F} \mathrm{~cm}^{-2}\right)$ was obtained (Figure 7E) from the galvanostatic discharge data at a current density of $2 \mathrm{~mA} \mathrm{~cm}^{-2}$. The capacitance decreased with increasing 


\section{WILEY-VCH}

scan rate (Figure 7C) and with increasing current density (Figure 7E) due to electrolyte diffusion limitations in pores of the electrodes. Figure7F and Supporting Information Figure S7 indicate that bending (up to $135^{\circ}$ ), twisting and partial compression (Figure 8A) do not significantly change in the CV shape and associated capacitance, calculated from the CV data. The cells showed a capacitance retention of 93.4 and $86.9 \%$, Coulombic efficiency of 100 and 93.3\%, after 1000 and 5000 cycles, respectively (Figure 7G).

The Ragone plot presented in Figure $7 \mathrm{H}$ indicates that the devices have promising power-energy characteristics. Figure 8B shows that the aerogel-based electrodes can be used for powering LED bulbs with a current of $20 \mathrm{~mA}$. The use of CNC-MWCNT aerogels impregnated with PPy as electrodes offers advantages, compared to graphene aerogels supports, which collapse under compression ${ }^{[47]}$. Moreover, in contrast to previously reported work $^{[47]}$ the compressibility of CNC-MWCNT-PPy electrodes results from the compressibility of CNC-MWCNT aerogel current collectors, which can be loaded with various active materials potentially with even higher mass loadings. The large size of the CNC-MWCNT-PPy electrodes is another benefit, compared to wire-shaped stretchable supercapacitors $^{[50]}$. The use of MWCNT for the fabrication of the aerogel based support and its loading with active PPy material by in situ PPy polymerization allowed for significant improvement in capacitance and mechanical properties, compared to our previous investigation, involving synthesis of capacitive particles and their subsequent incorporation in the CNC aerogels ${ }^{[51]}$. The use of TCH as an advanced dispersant for MWCNT instead of functionalized $\mathrm{SWCNT}^{[37]}$ and incorporation of MWCNT into the microstructure of the aerogel current collector allowed for significant reduction in electrode impedance, which in turn resulted in improved capacitance retention, especially at high charge-discharge rates. 


\section{WILEY-VCH}
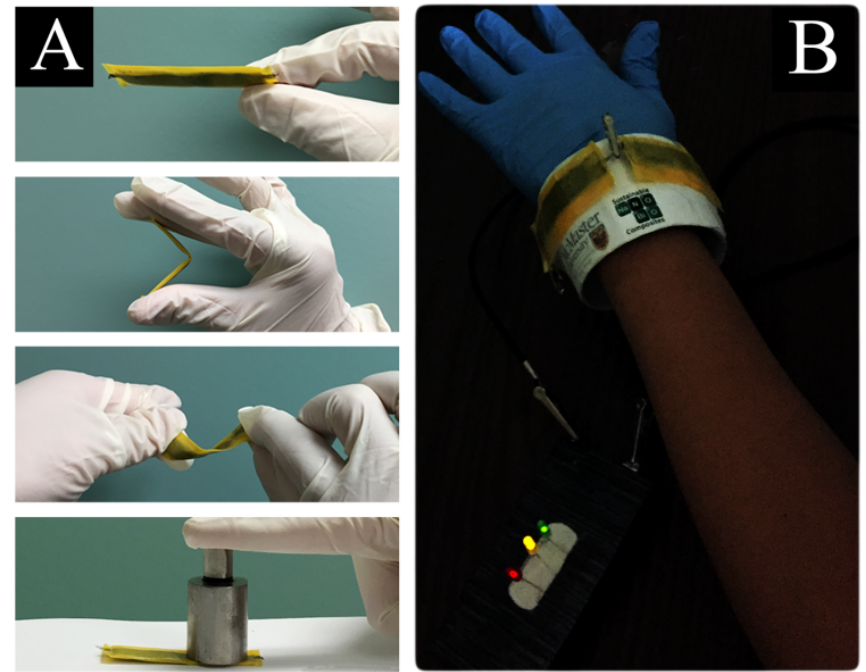

Figure 8. (A) ES cell: as fabricated and under bending, twisting and partially compressing stress, (B) wearable cells which are connected in series are able to power LED bulbs.

\section{Conclusions}

CNC-MWCNT hybrid aerogels were prepared by incorporating well-dispersed MWCNT during the crosslinking step of aerogel production. The use of bile acid as a dispersant for MWCNT offered advantages of improved electrochemical performance, compared to traditional head-and-tail surfactants. The aerogel diameter could be varied from 1 to $30 \mathrm{~cm}$ giving uniform, robust, lightweight and free-standing structures. This aerogel production strategy has opened a path for the fabrication of PPy-based electrodes with active mass loading of $0-17.8 \mathrm{mg} \mathrm{cm}^{-2}$ based on in situ polymerization of Py inside the CNCMWCNT aerogel. The resulting CNC-MWCNT-PPy electrodes were flexible and compressible with high capacitance.

Building on the processing advantages offered by our approach, we have demonstrated the fabrication of lightweight electrodes with capacitances as high as $2.1 \mathrm{~F} \mathrm{~cm}^{-2}$ and mass ratio of active material/current collector of 0.57 . Another major finding of this study is that electrodes showed excellent cyclic compressibility at strains in the range of $0-80 \%$. The electrodes and devices showed good capacitance retention at high charge-discharge rates and good cyclic stability and capacitance stability during compression and bending cycles. The 


\section{WILEY-VCH}

results of this investigation pave the way for the fabrication of supercapacitors for wearable electronic devices and other applications.

\section{Experimental Section}

4.1 Materials. Multi-walled carbon nanotubes (MWCNT) were obtained from Arkema, USA. Cellulose nanocrystals (CNC) with surface carboxyl groups (COOH-CNC), prepared by oxidation of wood pulp with ammonium persulfate (APS), ${ }^{[52]}$ were supplied by Advanced Cellulosic Material, formerly BioVision Technology, Inc. (New Minas, NS, Canada) and sulfuric acid-hydrolyzed CNC were produced in-house from cotton. ${ }^{[53]}$ Purified water was used with a resistivity of $18.2 \mathrm{M} \Omega \mathrm{cm}$ (Barnstead NANOpure DIamond system, Thermo Scientific, Asheville, NC, USA). Sodium dodecyl sulfate (SDS), taurocholic acid sodium salt (TCH), pyrrole (Py), 4,5-dihydroxy-1,3-benzenedisulfonic acid disodium salt (Tiron), sodium sulfate and APS were purchased from Sigma-Aldrich, USA. Py was stored in a refrigerator at $4{ }^{\circ} \mathrm{C}$ before use.

4.2. Preparation of Modified CNC. Aldehyde-modified CNC (CHO-CNC) and hydrazidemodified $\mathrm{CNC}\left(\mathrm{NHNH}_{2}-\mathrm{CNC}\right)$ were synthesized following our previous work using straightforward water-based reactions only. ${ }^{[32,54]}$ The functional density for CHO-CNC and $\mathrm{NHNH}_{2}-\mathrm{CNC}$ was measured to be $0.9 \pm 0.1$ and $0.14 \pm 0.02 \mathrm{mmol} / \mathrm{g} \mathrm{CNC}$, respectively, by conductometric titration. ${ }^{[55,56]}$ The average dimensions of modified CNC, prepared by this method, were $155 \times 4.1 \mathrm{~nm}$ and $129 \times 4.8 \mathrm{~nm}$ (length $\times$ width) as determined from transmission electron microscopy. Both types of modified CNC were stored in aqueous suspension format $(1.0 \mathrm{wt} . \%)$ at $4^{\circ} \mathrm{C}$.

4.3. Preparation of CNC-MWCNT Hybrid Aerogels. A stable MWCNT suspension (2 wt.\%) was obtained after sonication for $15 \mathrm{~min}$ in the presence of TCH or SDS as dispersants (1 wt.\%). In a typical procedure, $5 \mathrm{~mL}$ of the MWCNT suspension were mixed with $5 \mathrm{~mL}$ CHO-CNC (1 wt.\%) and $5 \mathrm{~mL} \mathrm{NHNH}{ }_{2}-\mathrm{CNC}(1 \mathrm{wt} . \%)$ in separated steps using a vortex mixer for 2 min (Level 8, Analog Vortex Mixer, VWR, Canada). For mechanical testing, the final 


\section{WILEY-VCH}

MWCNT suspension was transferred into a cylindrical glass vial (14.5 $\mathrm{mm}$ in diameter) and allowed to set for another $10 \mathrm{~min}$ before transfer into the freezer $\left(-20^{\circ} \mathrm{C}\right)$. The hybrid aerogels were obtained by freeze-drying the ice-gel. For the fabrication of supercapacitor electrodes, a stainless steel mesh was incorporated into the suspended mixture before it was placed in the freezer. The mesh allowed for reduced contact resistance in the electrode.

\subsection{Loading of CNC-MWCNT Aerogel Current Collector with PPy Active Material.} The loading of CNC-MWCNT aerogel current collector with PPy active material was performed by in situ polymerization of Py using APS as the initiator and Tiron as a dopant for PPy. In this method, $1.57 \mathrm{~g}$ Tiron $(5 \mathrm{mmol})$ was dissolved in $100 \mathrm{~mL}$ de-ionized water, containing as-prepared CNC-MWCNT aerogel, and $0.69 \mathrm{~mL}(10 \mathrm{mmol})$ Py was injected. Then $50 \mathrm{~mL}$ of $0.25 \mathrm{~mol} \mathrm{~L}^{-1}$ APS solution was slowly added to the solution. The resultant mixture was subsequently allowed to react for 5-60 min. The fabricated PPy loaded CNCMWCNT aerogels were washed with de-ionized water and ethanol.

4.5. Microstructure Characterization. A JEOL 7000F scanning electron microscope (SEM, JEOL Ltd., Japan) was used for microstructure characterization. Aerogels were immersed in liquid nitrogen and fractured to image their inner structure. A $5 \mathrm{~nm}$ thick platinum coating was applied before the SEM imaging.

4.6. Aerogel Mechanical Properties and Shape Recovery Ability. Aerogels with different PPy contents were tested using a compress and release routine on a Mach-1 Mechanical Testing System (Biomomentum, Canada). Each aerogel was made into a cylinder shape with a diameter of $14.5 \mathrm{~mm}$. The tests were carried out either in open-air or saturated $\mathrm{Na}_{2} \mathrm{SO}_{4}$ electrolyte, the maximum compression strain $(\varepsilon)$ was set to 0.8 , the speed of compression and release was $0.05 \mathrm{~cm} / \mathrm{s}$. Three individual aerogel samples were tested for each type of hybrid aerogel. The shape recovery ability was assessed by calculating the recovery percentage using equation $(1)$, in which the original height $\left(\mathrm{h}_{\text {org }}\right)$ and final height $\left(\mathrm{h}_{f i n}\right)$ were measured: 


\section{WILEY-VCH}

Shape Recovery Percentage $(\%)=\mathrm{h}_{\text {fin }} / \mathrm{h}_{\text {org }} \times 100 \%$

4.7. Electrochemical Studies. The capacitive behavior of electrodes and cells was studied in $0.5 \mathrm{M} \mathrm{Na}_{2} \mathrm{SO}_{4}$ aqueous solutions as an electrolyte. Cyclic voltammetry (CV) and impedance spectroscopy investigations were performed using a potentiostat (PARSTAT 2273, Princeton Applied Research, USA). Capacitive behavior of single electrodes was studied in threeelectrode cells. The area of the working electrode was $1 \mathrm{~cm}^{2}$. The counter electrode was a platinum gauze, and the reference electrode was a standard calomel electrode (SCE). CV studies were performed at scan rates of $2-100 \mathrm{mV} \mathrm{s}^{-1}$. The total capacitance $\mathrm{C}=\mathrm{Q} / \Delta \mathrm{V}$ was calculated using half the integrated area of the $\mathrm{CV}$ curve to obtain the charge $\mathrm{Q}$, and subsequently dividing the charge $\mathrm{Q}$ by the width of the potential window $\Delta \mathrm{V}$. Galvanostatic charge-discharge (CD) tests were carried out using a battery analyzer (BST8, MTI corporation, USA) at current densities of $2-100 \mathrm{~mA} \mathrm{~cm}^{-2}$. The total capacitance was calculated using the equation $\mathrm{C}=\mathrm{I} \Delta \mathrm{t} / \Delta \mathrm{V}$, where $\mathrm{I}$ is the constant discharge current, $\Delta \mathrm{t}$ is the discharge time, and $\Delta \mathrm{V}$ is the voltage window. The mass and area normalized capacitances of individual electrodes, $\mathrm{C}_{\mathrm{m}}=\mathrm{C} / \mathrm{m}$ (where $\mathrm{m}$ is the active mass of the electrode), $\mathrm{C}_{\mathrm{s}}=\mathrm{C} / \mathrm{S}$ (where $\mathrm{S}$ is the electrode area) and cell capacitances $\mathrm{C}_{\mathrm{cm}}=\mathrm{C} / 2 \mathrm{~m}, \mathrm{C}_{\mathrm{cs}}=\mathrm{C} / \mathrm{S}$ were analyzed.

The alternating current (AC) measurements of complex impedance $Z^{*}=Z^{\prime}-i Z^{\prime \prime}$ were performed in the frequency range of $10 \mathrm{mHz}$ to $100 \mathrm{kHz}$ at the amplitude of the AC signal of $5 \mathrm{mV}$. The complex capacitance $\mathrm{C}^{*}=\mathrm{C}^{\prime}-i \mathrm{C}^{\prime \prime}$ was calculated from the impedance data as $\mathrm{C}^{\prime}=\mathrm{Z}^{\prime \prime} / \omega|\mathrm{Z}|^{2}$ and $\mathrm{C}^{\prime \prime}=\mathrm{Z}^{\prime} / \omega|\mathrm{Z}|^{2}$, where $\omega=2 \pi f$ (f-frequency). The electrochemical performance under compression at different strains was measured using three-electrode configuration cells. A digital caliper was employed to measure the deformation of the aerogel. In addition, the CVs of supercapacitor cells were in situ tested during bending, twisting and compression.

\section{Supporting Information}

Supporting Information is available from the Wiley Online Library or from the author. 


\section{WILEY-VCH}

\section{Acknowledgements}

The authors gratefully acknowledge NSERC Canada and the Faculty of Engineering at McMaster University for the financial support.

Received: ((will be filled in by the editorial staff))

Revised: ((will be filled in by the editorial staff))

Published online: ((will be filled in by the editorial staff))

[1] T. Brousse, P.-L. Taberna, O. Crosnier, R. Dugas, P. Guillemet, Y. Scudeller, Y. Zhou, F. Favier, D. Bélanger, P. Simon, J. Power Sources 2007, 173, 633.

[2] B. E. Conway, W. G. Pell, J. Power Sources 2002, 105, 169.

[3] R. Kötz, M. Carlen, Electrochim. Acta 2000, 45, 2483.

[4] S. Porada, M. Bryjak, A. van der Wal, P. M. Biesheuvel, Electrochim. Acta 2012, 75, 148.

[5] S. Porada, L. Borchardt, M. Oschatz, M. Bryjak, J. Atchison, K. Keesman, S. Kaskel,

P. Biesheuvel, V. Presser, Energy Environ. Sci. 2013, 6, 3700.

[6] K. Shi, I. Zhitomirsky, Electrochim. Acta 2015, 174, 588.

[7] K. Shi, M. Ren, I. Zhitomirsky, ACS Sustainable Chem. Eng. 2014, 2, 1289.

[8] L. Wei, G. Yushin, Nano Energy 2012, 1, 552.

[9] D. Bélanger, T. Brousse, J. W. Long, Electrochem. Soc. Interface 2008, 17, 49.

[10] H. Gao, K. Lian, RSC Adv. 2014, 4, 33091.

[11] W. Gu, M. Sevilla, A. Magasinski, A. B. Fuertes, G. Yushin, Energy Environ.Sci. 2013, 6, 2465.

[12] P. Simon, Y. Gogotsi, Nature Mater. 2008, 7, 845.

[13] G. A. Snook, P. Kao, A. S. Best, J. Power Sources 2011, 196, 1.

[14] K. Gao, Z. Shao, X. Wang, Y. Zhang, W. Wang, F. Wang, RSC Adv. 2013, 3, 15058.

[15] Z. Gui, H. Zhu, E. Gillette, X. Han, G. W. Rubloff, L. Hu, S. B. Lee, ACS Nano 2013, $7,6037$.

[16] Q. Niu, K. Gao, Z. Shao, Nanoscale 2014, 6, 4083. 


\section{WILEY-VCH}

[17] J. X. Feng, S. H. Ye, A. L. Wang, X. F. Lu, Y. X. Tong, G. R. Li, Adv. Funct. Mater. 2014, 24, 7093.

[18] Y. J. Kang, S.-J. Chun, S.-S. Lee, B.-Y. Kim, J. H. Kim, H. Chung, S.-Y. Lee, W. Kim, ACS Nano 2012, 6, 6400 .

[19] S. Li, D. Huang, B. Zhang, X. Xu, M. Wang, G. Yang, Y. Shen, Adv. Energy Mater. 2014, 4, 1301655.

[20] X. Wu, J. Tang, Y. Duan, A. Yu, R. M. Berry, K. C. Tam, J. Mater. Chem. A 2014, 2, 19268.

[21] S. Y. Liew, D. A. Walsh, W. Thielemans, RSC Adv. 2013, 3, 9158.

[22] X. Wu, V. L. Chabot, B. K. Kim, A. Yu, R. M. Berry, K. C. Tam, Electrochim. Acta $\mathbf{2 0 1 4}, 138,139$.

[23] A. Razaq, L. Nyholm, M. Sjödin, M. Strømme, A. Mihranyan, Adv. Energy Mater. $\mathbf{2 0 1 2}, 2,445$.

[24] Z. Wang, D. O. Carlsson, P. Tammela, K. Hua, P. Zhang, L. Nyholm, M. Strømme, ACS Nano 2015, 9, 7563.

[25] P. Tammela, Z. Wang, S. Frykstrand, P. Zhang, I.-M. Sintorn, L. Nyholm, M. Strømme, RSC Adv. 2015, 5, 16405.

[26] D. Ge, L. Yang, L. Fan, C. Zhang, X. Xiao, Y. Gogotsi, S. Yang, Nano Energy 2015, 11,568 .

[27] F. Jiang, Y.-L. Hsieh, J. Mater. Chem. A 2014, 2, 6337.

[28] H.-D. Huang, C.-Y. Liu, D. Zhou, X. Jiang, G.-J. Zhong, D.-X. Yan, Z.-M. Li, J. Mater. Chem. A 2015, 3, 4983.

[29] H. Wang, Y. Gong, Y. Wang, RSC Adv. 2014, 4, 45753.

[30] X. Zhang, K. S. Ziemer, K. Zhang, D. Ramirez, L. Li, S. Wang, L. J. Hope-Weeks, B. L. Weeks, ACS Appl. Mater. Interfaces 2015, 7, 1057. 


\section{WILEY-VCH}

[31] M. Hamedi, E. Karabulut, A. Marais, A. Herland, G. Nyström, L. Wågberg, Angew. Chem. Int. Ed. 2013, 52, 12038.

[32] X. Yang, E. D. Cranston, Chem. Mater. 2014, 26, 6016.

[33] D. O. Carlsson, G. Nyström, Q. Zhou, L. A. Berglund, L. Nyholm, M. Strømme, J. Mater. Chem. 2012, 22, 19014.

[34] X. Zhang, Z. Lin, B. Chen, W. Zhang, S. Sharma, W. Gu, Y. Deng, J. Power Sources 2014, 246, 283.

[35] Y. Liu, J. Zhou, J. Tang, W. Tang, Chem. Mater. 2015, 27, 7034.

[36] Z. Shi, H. Gao, J. Feng, B. Ding, X. Cao, S. Kuga, Y. Wang, L. Zhang, J. Cai, Angew. Chem. Int. Ed. 2014, 53, 5380.

[37] G. Nyström, A. Marais, E. Karabulut, L. Wågberg, Y. Cui, M. M. Hamedi, Nature Commun. 2015, 6, 7259.

[38] S. Lin, D. Blankschtein, J. Phys. Chem. B 2010, 114, 15616.

[39] M. Ata, I. Zhitomirsky, J. Colloid Interface Sci. 2015, 454, 27.

[40] W. Wenseleers, I. I. Vlasov, E. Goovaerts, E. D. Obraztsova, A. S. Lobach, A. Bouwen, Adv. Funct. Mater. 2004, 14, 1105.

[41] J.-Y. Hong, B. M. Bak, J. J. Wie, J. Kong, H. S. Park, Adv. Funct. Mater. 2015, 25, 1053.

[42] Y. Zhu, K. Shi, I. Zhitomirsky, J. Power Sources 2014, 268, 233.

[43] L. J. Gibson, M. F. Ashby, Cellular solids: structure and properties, Cambridge university press, 1999.

[44] H. Sehaqui, M. Salajková, Q. Zhou, L. A. Berglund, Soft Matter 2010, 6, 1824.

[45] R. T. Olsson, M. A. Samir, G. Salazar-Alvarez, L. Belova, V. Ström, L. A. Berglund, O. Ikkala, J. Nogues, U. W. Gedde, Nature Nanotechnol. 2010, 5, 584.

[46] B. Wicklein, A. Kocjan, G. Salazar-Alvarez, F. Carosio, G. Camino, M. Antonietti, L. Bergström, Nature Nanotechnol. 2015, 10, 277. 


\section{WILEY-VCH}

[47] Y. Zhao, J. Liu, Y. Hu, H. Cheng, C. Hu, C. Jiang, L. Jiang, A. Cao, L. Qu, Adv.

Mater. 2013, 25, 591.

[48] Z. Niu, W. Zhou, X. Chen, J. Chen, S. Xie, Adv. Mater. 2015, 27, 6002.

[49] P. Li, C. Kong, Y. Shang, E. Shi, Y. Yu, W. Qian, F. Wei, J. Wei, K. Wang, H. Zhu, A.

Cao, D. Wu, Nanoscale 2013, 5, 8472.

[50] T. Chen, R. Hao, H. Peng, L. Dai, Angew. Chem. Int. Ed. 2015, 54, 618.

[51] X. Yang, K. Shi, I. Zhitomirsky, E. D. Cranston, Adv. Mater. 2015, 27, 6104.

[52] A. C. Leung, S. Hrapovic, E. Lam, Y. Liu, K. B. Male, K. A. Mahmoud, J. H. Luong, Small 2011, 7, 302.

[53] K. H. Kan, J. Li, K. Wijesekera, E. D. Cranston, Biomacromolecules 2013, 14, 3130.

[54] X. Yang, E. Bakaic, T. Hoare, E. D. Cranston, Biomacromolecules 2013, 14, 4447.

[55] S. Beck, M. Méthot, J. Bouchard, Cellulose 2015, 22, 101.

[56] S. B. Campbell, M. Patenaude, T. Hoare, Biomacromolecules 2013, 14, 644.

\section{Figure captions}

Figure 1. (A) Chemical structures and (B) MWCNT dispersion mechanisms of SDS and TCH, (C) scheme of CNC-MWCNT aerogel fabrication method, (D) aerogel with a density of $21 \pm$ $3 \mathrm{mg} \mathrm{cm}^{-3}$ attached to a weighing dish through static electricity.

Figure 2. (A) CNC-MWCNT aerogel, prepared using $\mathrm{TCH}$, containing a $0.2 \mathrm{~mm}$ thickness stainless steel mesh current collector and SEM images of (B) cross section, showing the stainless steel mesh inside the aerogel and (C, D) aerogel cross section at different magnifications.

Figure 3. (A) Mass of PPy, deposited on CNC-MWCNT aerogel, prepared using TCH, versus polymerization time and (B-E) SEM images of the CNC-MWCNT aerogels with PPy mass loadings of $3.8,6.1$ and $17.8 \mathrm{mg} \mathrm{cm}^{-2}$ at different magnifications.

Figure 4. (A,B) CVs for CNC-MWCNT aerogels, prepared using TCH, with PPy loadings of (A) 6.1 and (B) $17.8 \mathrm{mg} \mathrm{cm}^{-2}$ at scan rates of (a) 2, (b) 5 and (c) $10 \mathrm{mV} \mathrm{s}^{-1}$. (C) Nyquist plots of complex impedance and (D) $\mathrm{C}^{\prime}$ calculated from the impedance data for aerogel with PPy 


\section{WILEY-VCH}

loadings of 6.1 and $17.8 \mathrm{mg} \mathrm{cm}^{-2}$. (E) $\mathrm{C}_{\mathrm{m}}$ and $\mathrm{C}_{\mathrm{s}}$ calculated from $\mathrm{CV}$ s versus scan rate, $(\mathrm{F})$ capacitance retention versus cycle number (inset shows corresponding CVs at $50 \mathrm{mV} \mathrm{s}^{-1}$ after (a) $1^{\text {st }}$, (b) $250^{\text {th }}$, (c) $500^{\text {th }}$, (d) $750^{\text {th }}$ and (e) $1000^{\text {th }}$ cycles for aerogel with PPy loading of 6.1 $\mathrm{mg} \mathrm{cm} \mathrm{cm}^{-2}$.

Figure 5. (A) $\mathrm{C}_{\mathrm{s}}$ versus active mass of PPy, grown on CNC-MWCNT aerogel, prepared using $\mathrm{TCH}$, at scan rates of (a) 2, (b) 5, (c) 10 , (d) 20 , (e) 50 and (f) $100 \mathrm{mV} \mathrm{s}^{-1}$. (B) $\mathrm{C}_{\mathrm{m}}$ and $\mathrm{C}_{\mathrm{t}}$ at 2 $\mathrm{mV} \mathrm{s}^{-1}$ versus active mass of PPy, grown on CNC-MWCNT aerogel.

Figure 6. (A) Compressive stress-strain curves for CNC-MWCNT aerogels, prepared using $\mathrm{TCH}$, with different PPy loadings in the range of $0-17.8 \mathrm{mg} \mathrm{cm}^{-2}$, (inset shows initial parts of the curves). (B) Compression tests of PPy loaded CNC-MWCNT aerogels at 0-80\% strains. (C) Shape recovery of pure CNC-MWCNT aerogel with PPy contents of $0,6.1$ and $17.8 \mathrm{mg}$ $\mathrm{cm}^{-2}$ after 400 cyclic compressions from $0 \%$ to $80 \%$ strain. (D) CVs for CNC-MWCNT aerogel with PPy mass loading of $6.1 \mathrm{mg} \mathrm{cm}^{-2}$ at a scan rate of $20 \mathrm{mV} \mathrm{s}^{-1}$ under different strains $(20-80 \%)$. All the tests were carried out in $0.5 \mathrm{M} \mathrm{Na}_{2} \mathrm{SO}_{4}$ solutions.

Figure 7. (A) Scheme of ES cell, (B-G) testing data for the cell with PPy mass of $6.1 \mathrm{mg} \mathrm{cm} \mathrm{cm}^{-2}$ for each electrode: (B) CVs at scan rates of (a) 2, (b) 5, (c) 10, (d) 20, (e) 50 and (f) $100 \mathrm{mV} \mathrm{s}^{-}$ ${ }^{1}$, (C) $\mathrm{C}_{\mathrm{cm}}$ and $\mathrm{C}_{\mathrm{cs}}$ calculated from the $\mathrm{CV}$ data versus scan rate, (D) charge-discharge behavior at current densities of (a) 2, (b) 3, (c) 4, (d) 6 and (e) $8 \mathrm{~mA} \mathrm{~cm}^{-2}$, (E) $\mathrm{C}_{\mathrm{cm}}$ and $\mathrm{C}_{\mathrm{cs}}$ calculated from the $\mathrm{CD}$ data versus current density, $(\mathrm{F}) \mathrm{CVs}$ at a scan rate of $2 \mathrm{mV} \mathrm{s}^{-1}$ for different deformations, $(\mathrm{G})$ capacitance retention and Coulombic efficiency versus cycle number (inset shows initial and final charge-discharge curves at $\left.15 \mathrm{~mA} \mathrm{~cm}^{-2}\right),(\mathrm{H})$ Ragone plots for cells with PPy mass of individual electrodes of 6.1 and $17.8 \mathrm{mg} \mathrm{cm}^{-2}$.

Figure 8. (A) ES cell: as fabricated and under bending, twisting and partially compressing stress, (B) wearable cells which are connected in series are able to power LED bulbs. 


\section{WILEY-VCH}

Keyword: cellulose, nanocrystal, polypyrrole, supercapacitor, aerogel

Authors: Kaiyuan Shi ${ }^{a \dagger}$, Xuan Yang ${ }^{b \dagger}$, Emily D. Cranston ${ }^{b}$ and Igor Zhitomirsky ${ }^{a *}$ $\dagger$ These authors contributed equally to this work

Title: Efficient lightweight supercapacitor with compression stability

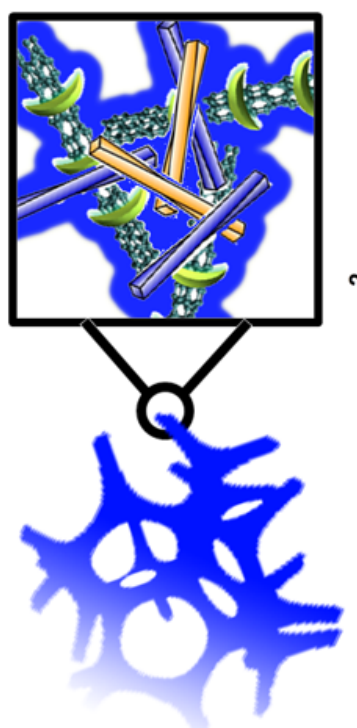

In situ polymerized PPy in nanocellulose-CNT aerogel

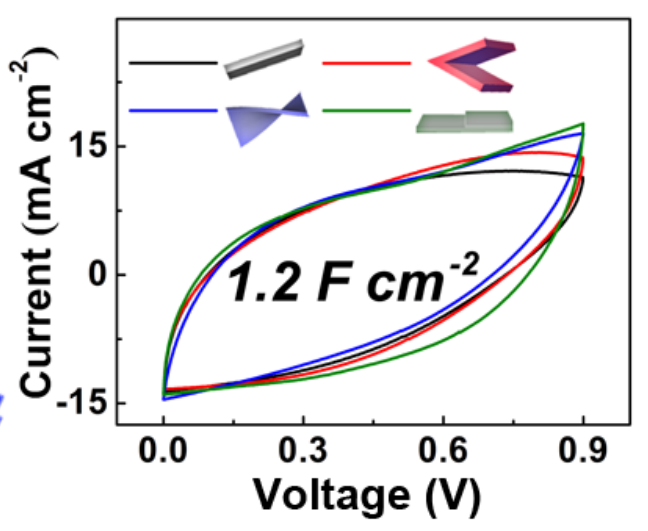




\section{WILEY-VCH}

\section{Supporting Information}

\section{Efficient lightweight supercapacitor with compression stability}

Kaiyuan Shi ${ }^{a \dagger}$, Xuan Yang ${ }^{b \dagger}$, Emily D. Cranston ${ }^{b}$ and Igor Zhitomirsky ${ }^{a *}$

$\dagger$ These authors contributed equally to this work

Kaiyuan Shi, Prof. Igor Zhitomirsky*

Department of Materials Science and Engineering, McMaster University, Hamilton, L8S 4L7, Canada

E-mail: zhitom@mcmaster.ca

Phone: 1- (905)-525-9140 ext. 23914

Xuan Yang, Prof. Emily D. Cranston

Department of Chemical Engineering, McMaster University, Hamilton, L8S 4L7, Canada

E-mail: ecranst@mcmaster.ca
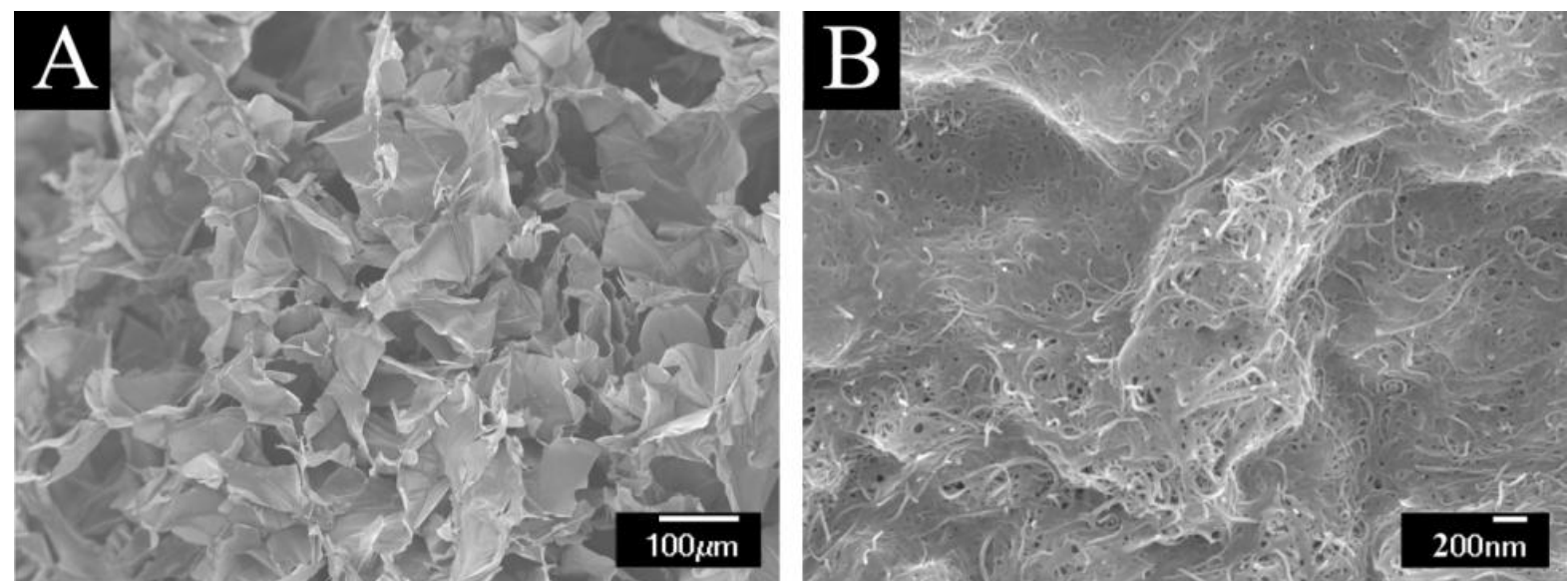

Figure S1. SEM images at different magnifications of CNC-MWCNT aerogel, prepared using SDS as a dispersant for MWCNT.

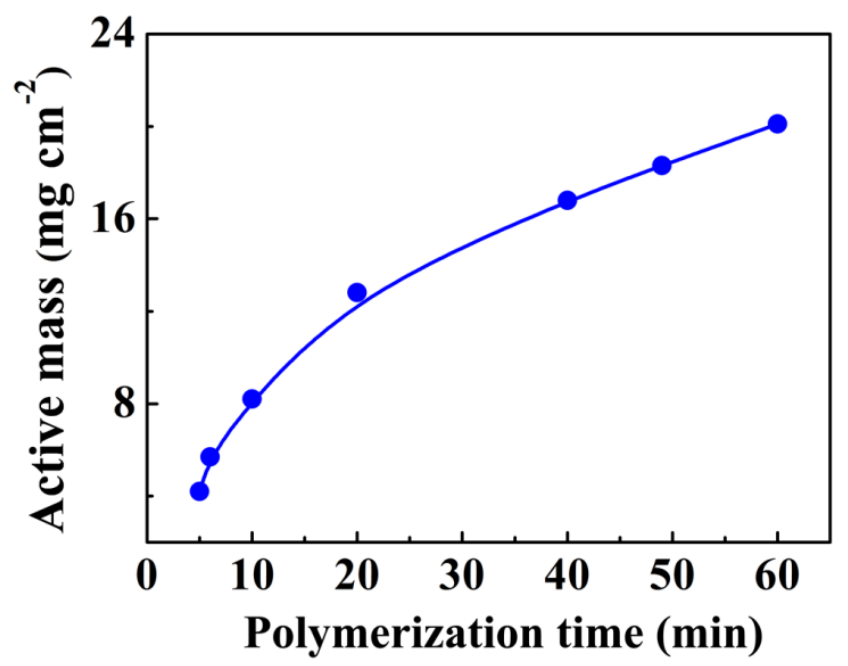

Figure S2. Mass of PPy, deposited on CNC-MWCNT aerogel, prepared using SDS, as a function of polymerization time. 


\section{WILEY-VCH}
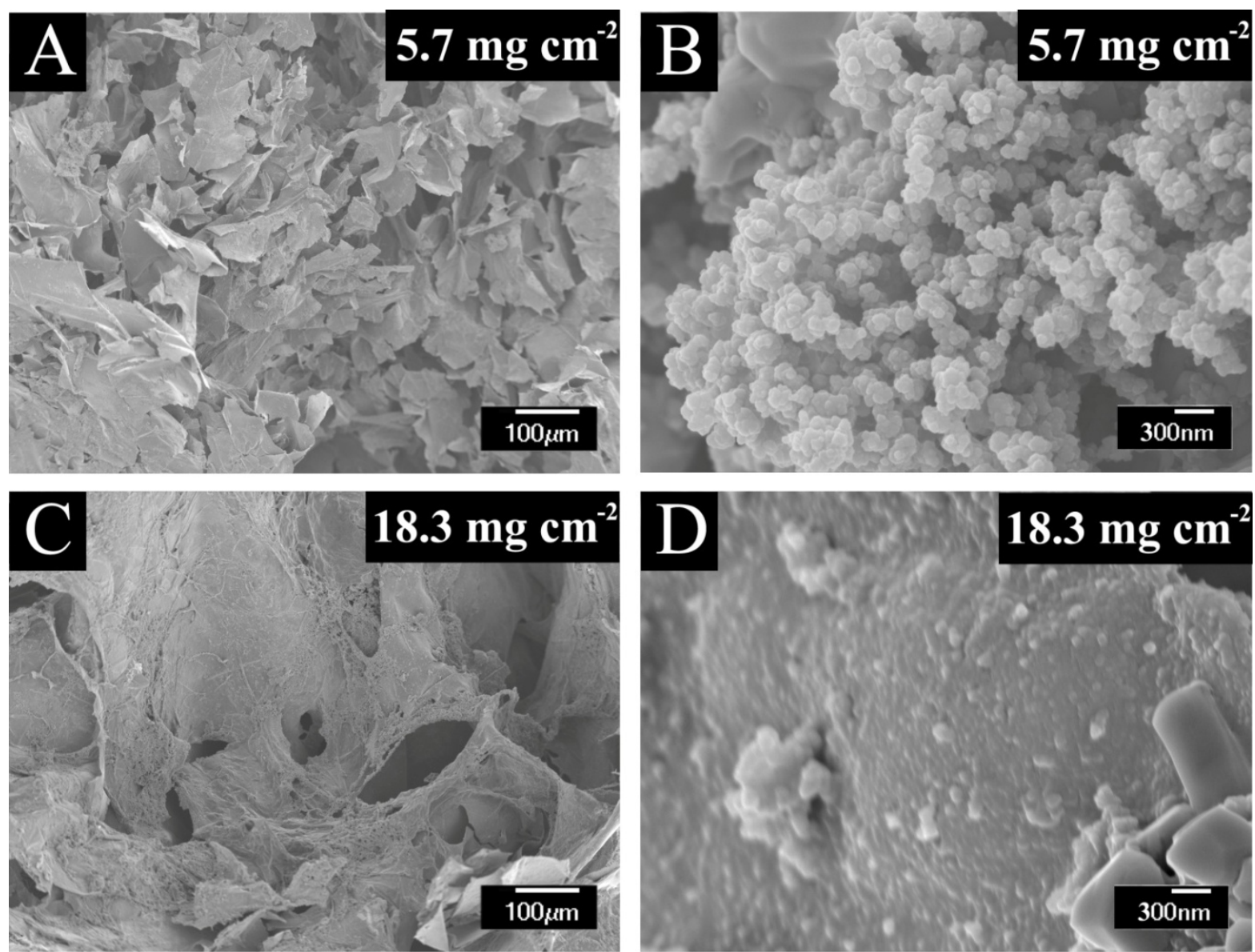

Figure S3. SEM images of CNC-MWCNT aerogels, prepared using SDS, with PPy mass loadings of (A and B) 5.7 and $\left(C\right.$ and D) $18.3 \mathrm{mg} \mathrm{cm}^{-2}$ at different magnifications.
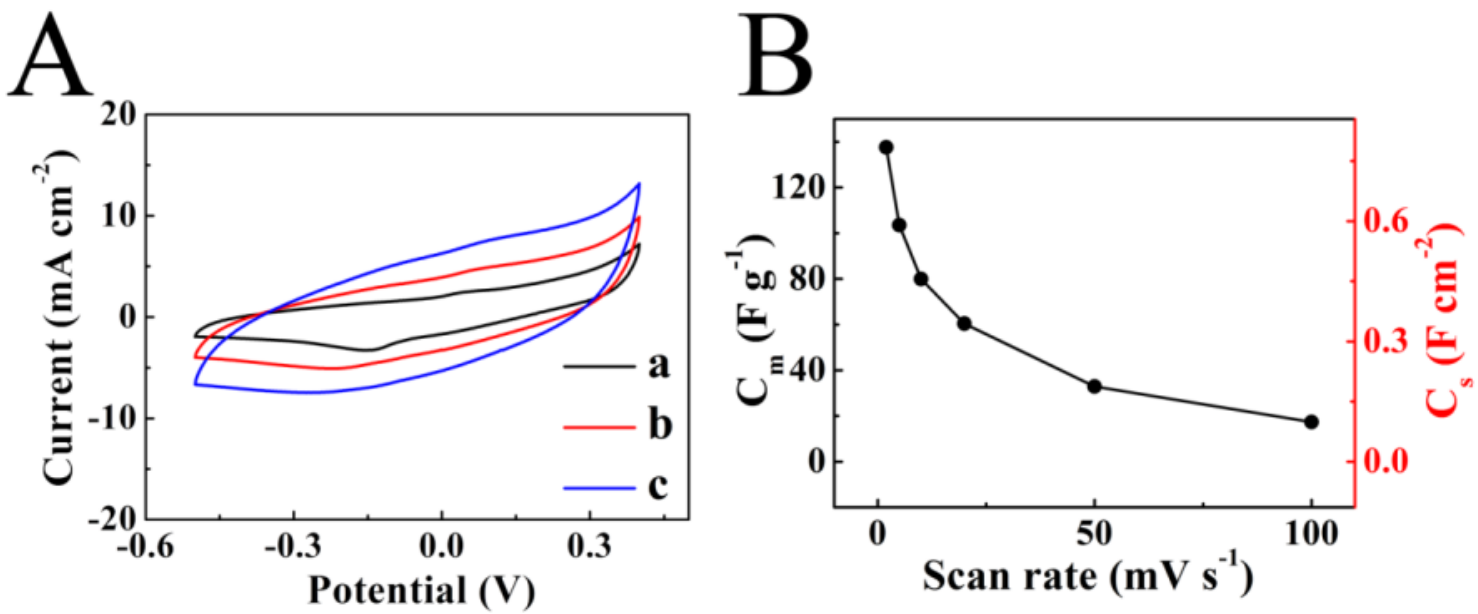

Figure S4. (A) CVs of PPy grown CNC-MWCNT aerogels prepared with SDS at scan rates of (a) 2, (b) 5 and (c) $10 \mathrm{mV} \mathrm{s}^{-1}$. (B) $\mathrm{C}_{\mathrm{m}}$ and $\mathrm{C}_{\mathrm{s}}$ calculated from CVs versus scan rate. The electrode had a PPy mass of $5.7 \mathrm{mg} \mathrm{cm}^{-2}$. 


\section{WILEY-VCH}

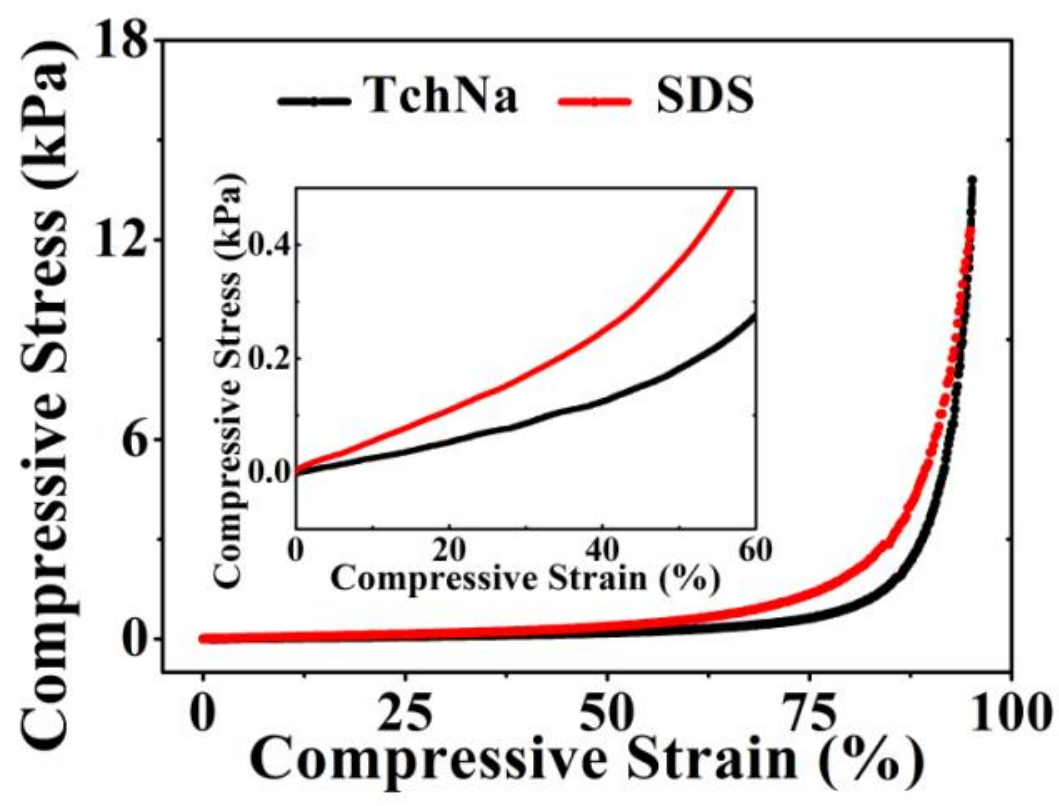

Figure S5. Compressive stress-strain curves for pure CNC-CNT aerogel prepared by TCH and SDS, inset shows the initial part of the curves.

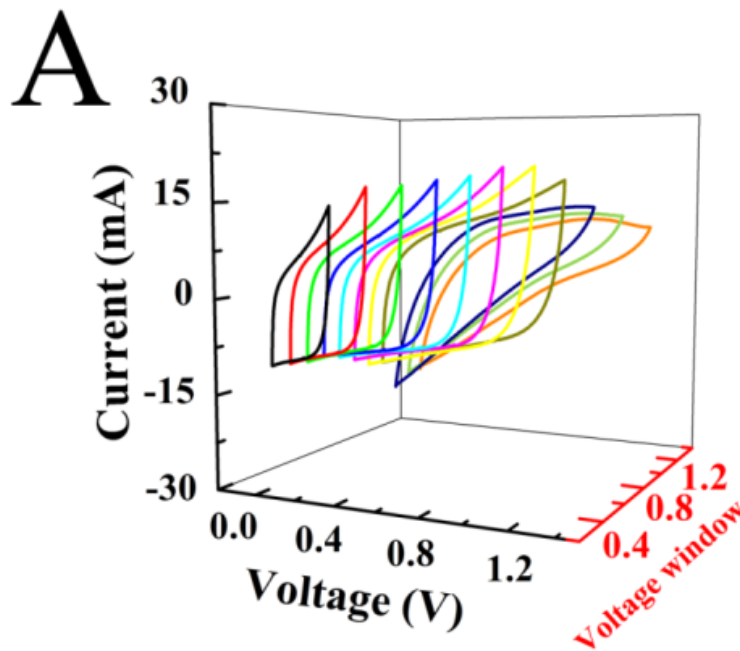

$\mathrm{B}$

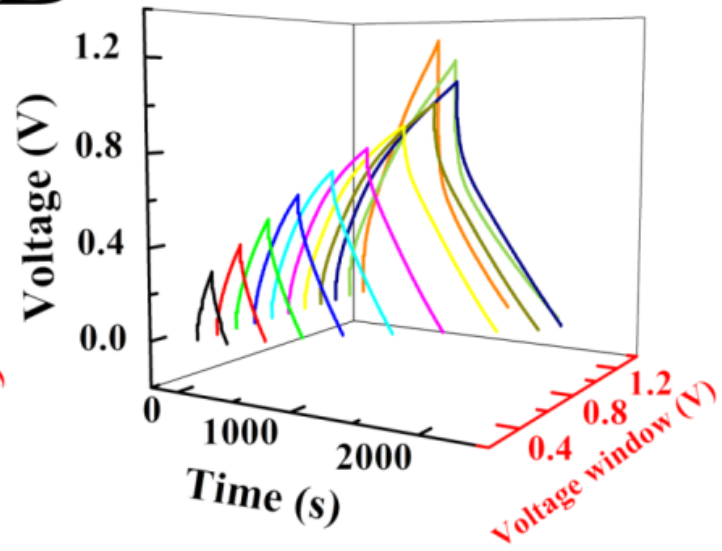

Figure S6. Capacitive behavior at different voltage windows for a symmetric supercapacitor, containing two PPy grown CNC-CNT aerogel electrodes with PPy mass of $6.1 \mathrm{mg} \mathrm{cm}^{-2}$ : (A) CVs at a scan rate of $2 \mathrm{mV} \mathrm{s}^{-1}$ and (B) CDs at a current density of $4 \mathrm{~mA} \mathrm{~cm}^{-2}$ in different voltage windows (from 0.3 to $1.3 \mathrm{~V}$, as indicated). 


\section{WILEY-VCH}

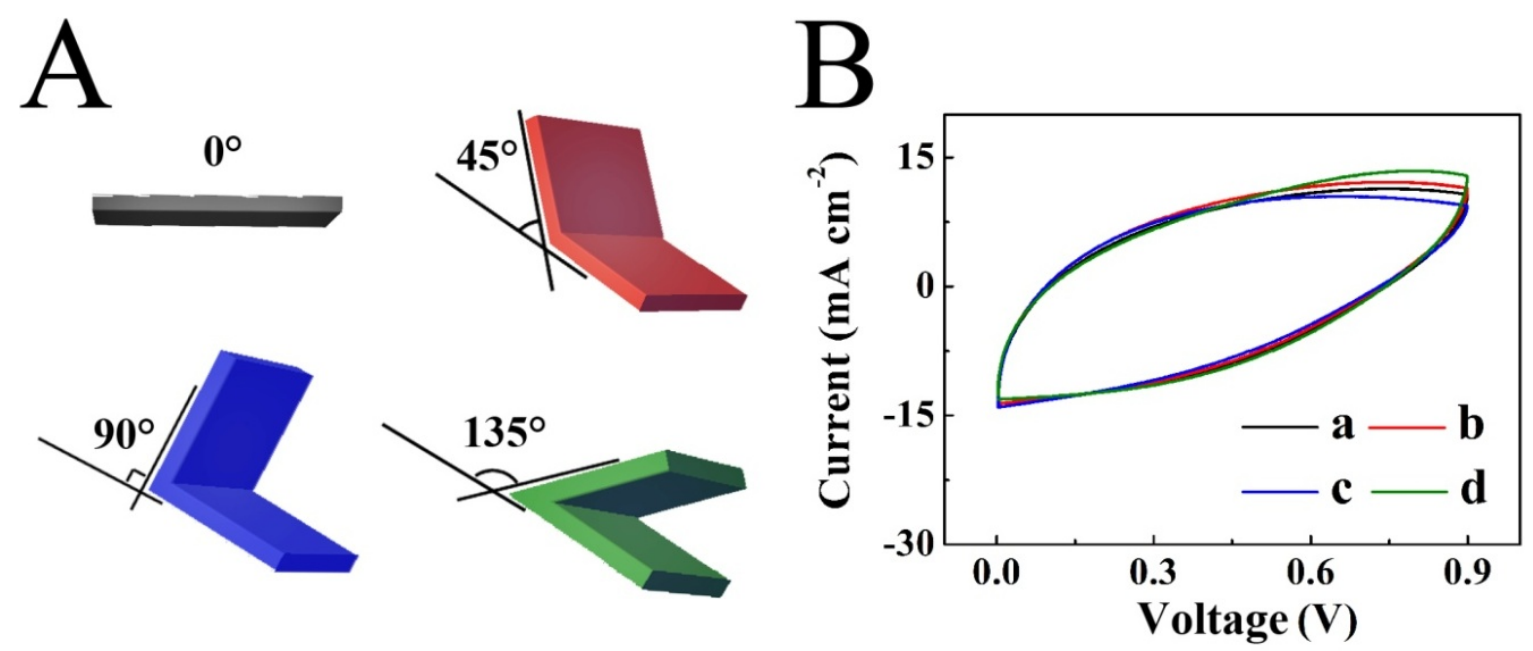

Figure S7. (A) Scheme of the symmetric supercapacitor bent in different angles. (B) CVs at a scan rate of $2 \mathrm{mV} \mathrm{s}^{-1}$ of symmetric supercapacitor (a) obtained without any deformations and (c-d) preformed in-site during (c) $45^{\circ}$, (d) $90^{\circ}$ and (d) $135^{\circ}$ bend. The symmetric supercapacitor was fabricated by two PPy grown CNC-CNT aerogel electrodes with PPy mass of $6.1 \mathrm{mg} \mathrm{cm}^{-2}$. 